\title{
Warm Handoffs and Attendance at Initial Integrated Behavioral Health Appointments
}

Christine A. Pace, MD, MSc ${ }^{1}$

Katberine Gergen-Barnett, $M D^{2}$

Alysa Veidis, RN, MSN, NP-BC ${ }^{3}$

Joanna D'Afflitti, MD, $M P H^{1}$

Jason Worcester, $M D^{1}$

Pedro Fernandez, $M D^{4}$

Karen E. Lasser, MD, MPH ${ }^{1}$

'Section of General Internal Medicine, Department of Medicine, Boston University School of Medicine and Boston Medical Center, Boston, Massachusetts

${ }^{2}$ Department of Family Medicine, Boston University School of Medicine and Boston Medical Center, Boston, Massachusetts

${ }^{3}$ Commonwealth Care Alliance, Boston, Massachusetts

${ }^{4}$ Department of Psychiatry, University of Texas Southwestern, Dallas, Texas

Conflicts of interest: authors report none.

\section{CORRESPONDING AUTHOR}

Christine Pace, MD, MSc

801 Massachusetts Ave, 2nd Floor

Boston, MA 02117

Christine.pace@bmc.org

\begin{abstract}
Though integrated behavioral health programs often encourage primary care physicians to refer patients by means of a personal introduction (warm handoff), data are limited regarding the benefits of warm handoffs. We conducted a retrospective study of adult primary care patients referred to behavioral health clinicians in an urban, safety-net hospital to investigate the association between warm handoffs and attendance rates at subsequent initial behavioral health appointments. In multivariable analyses, patients referred via warm handoffs were not more likely to attend initial appointments ( $\mathrm{OR}=0.96 ; 95 \% \mathrm{Cl}, 0.79-1.18 ; P=.71)$. A prospective study is necessary to confirm the role of warm handoffs.
\end{abstract}

Ann Fam Med 2018;16:346-348. https://doi.org/10.1370/afm.2263.

\section{INTRODUCTION}

W arm handoffs are a common and often recommended feature of programs that integrate behavioral health services into primary care. ${ }^{1}$ In a typical warm handoff, primary care clinicians refer patients to an integrated behavioral health clinician by directly introducing the patient. Warm handoffs have theoretical benefits, including building patients' trust in behavioral health clinicians and reducing patients' stigma about behavioral health care, which could translate to improved attendance at subsequent behavioral health appointments. Attendance to mental health appointments is low and a barrier to broadening access to care. ${ }^{2}$ Yet, whether warm handoffs improve attendance is unclear. Two previous studies have addressed this question with conflicting results. ${ }^{3,4}$ Because warm handoffs require investment of clinician time and physician training, more data regarding their benefit would be useful. Our objective was to determine whether warm handoffs are associated with improved attendance at subsequent initial integrated behavioral health appointments.

\section{METHODS}

Boston Medical Center is an urban safety-net hospital serving primarily minority and low-income patients. In 2014, the hospital-based general internal medicine and family medicine clinics began a program of integrated behavioral health in which mental health clinicians (primarily social workers) offer evaluation, short-course therapy, and substance use counseling to patients. Primary care clinicians can refer patients using either warm handoffs to the program clinicians, who meet with the patient and schedule an intake encounter, or by having front desk staff schedule an initial appointment. We conducted a retrospective analysis of clinical and scheduling data from new referrals to the integrated behavioral health program from July 1, 2015, to December 31, 2016. The primary independent variable was whether the patient had a warm handoff encounter with a mental health clinician before the initial appointment. The mental health clinicians noted a warm handoff in the electronic health record (EHR). The primary outcome was whether the patient attended their initial program appoint- 
ment. The institutional review board at Boston University Medical Center approved this study as exempt.

We used multiple logistic regression to examine the association between warm handoffs and the primary outcome variable. We included covariates in the adjusted models with a priori clinical relevance or statistically significance in bivariable analyses $(P \leq .2)$. Based on the hypothesis that such diagnoses might worsen attendance rates, we included the following

\section{Table 1. Characteristics of Patients Referred to the Integrated Behavioral Health Program in Primary Care, July 1, 2015 to December 31, 2016} $(\mathrm{N}=2,690)$

\begin{tabular}{|c|c|c|}
\hline Characteristic & $\begin{array}{c}\text { Percent } \\
\text { of } \\
\text { Total }\end{array}$ & $\begin{array}{l}\text { Attended Initial } \\
\text { Appointment } \\
\text { No. (\%) }\end{array}$ \\
\hline \multicolumn{3}{|l|}{ Age, y } \\
\hline $18-40$ & 50.04 & $514(38.19)$ \\
\hline $41-64$ & 44.68 & $511(42.51)$ \\
\hline$\geq 65$ & 5.28 & $62(43.66)$ \\
\hline Female sex & 58.74 & $611(38.67)$ \\
\hline \multicolumn{3}{|l|}{ Race/ethnicity } \\
\hline $\begin{array}{l}\text { Non-Hispanic black/ } \\
\text { African-American }\end{array}$ & 47.14 & $472(37.19)$ \\
\hline Non-Hispanic white & 24.05 & $292(45.13)$ \\
\hline Other or missing race & 9.44 & $113(44.49)$ \\
\hline Hispanic/Latino (any race) & 19.33 & $210(40.38)$ \\
\hline \multicolumn{3}{|l|}{ Primary language } \\
\hline English & 81.00 & $877(40.25)$ \\
\hline Non-English & 19.00 & $210(41.10)$ \\
\hline \multicolumn{3}{|l|}{ Insurance } \\
\hline Medicaid & 58.10 & $601(38.45)$ \\
\hline Medicare & 13.64 & $147(40.05)$ \\
\hline Commercial & 21.08 & $254(44.80)$ \\
\hline Other & 4.91 & $57(43.18)$ \\
\hline \multicolumn{3}{|l|}{ Behavioral health diagnoses ${ }^{a}$} \\
\hline Depression & 28.74 & $324(41.91)$ \\
\hline Anxiety & 17.06 & $186(40.52)$ \\
\hline Bipolar disorder & 2.90 & $36(46.15)$ \\
\hline Panic disorder & 2.23 & $21(35.00)$ \\
\hline PTSD & 6.58 & $82(46.33)$ \\
\hline Schizophrenia & 9.44 & $116(45.67)$ \\
\hline Substance use disorder & 18.25 & $192(39.10)$ \\
\hline \multicolumn{3}{|l|}{ Medical comorbidities } \\
\hline Type 2 diabetes & 15.43 & $171(41.20)$ \\
\hline $\begin{array}{l}\text { Chronic obstructive pulmo- } \\
\text { nary disease }\end{array}$ & 19.29 & $209(40.27)$ \\
\hline Received warm handoff & 20.15 & $221(40.77)$ \\
\hline \multicolumn{3}{|l|}{$\begin{array}{l}\text { Time from referral to scheduled } \\
\text { initial appointment }\end{array}$} \\
\hline Same day as referral & 6.80 & $150(81.97)$ \\
\hline$>1 \mathrm{~d}$, but $\leq 30 \mathrm{~d}$ after referral & 71.00 & $766(40.10)$ \\
\hline$>30 \mathrm{~d}$ after referral & 21.97 & $169(28.60)$ \\
\hline
\end{tabular}

potential confounders: substance use disorders, posttraumatic stress disorder (PTSD), bipolar disorder, and schizophrenia. ${ }^{2,5}$ Variance inflation factors for predictors were below 1.5, suggesting absence of collinearity. We performed a sensitivity analysis to determine whether the model would change if all same-day appointments were referred by warm handoffs. We were concerned that if the program clinicians converted warm handoffs into same-day initial appointments (as they did in 39 documented occurrences), they may not have documented warm handoffs in the EHR, leading us to undercount warm handoffs for this group of patients. All analyses were conducted using SAS 9.1 (SAS Institute Inc).

\section{RESULTS}

A total of 2,690 patients were scheduled for initial appointments with the behavioral health clinicians; a primary care clinician referred $21 \%$ using a warm handoff. Of these patients, 1,087 (40\%) attended initial behavioral health appointment (Table 1).

Table 2 shows results of multivariable analyses adjusting for age, sex, race, insurance, substance use disorders, bipolar disorder, PTSD, schizophrenia, and days until next appointment. Patients referred by warm handoffs did not have an increased odds of attending the initial appointment. Having an initial appointment scheduled within 30 days of the referral was significantly associated with attendance, and the association was even stronger when the initial appointment was scheduled to take place on the same day as the referral.

In the sensitivity analysis that assumed all same-day appointments were referred by warm handoffs, our findings did not change; we still failed to find an association between warm handoffs and attendance.

\section{DISCUSSION}

In this study, warm handoffs were not associated with improved attendance at initial behavioral health appointments. The most significant predictor of attendance at an initial appointment was time from referral until appointment, consistent with other studies in specialty mental health and other clinical settings. ${ }^{6-10}$

The retrospective design of this study allows for unmeasured confounding. Primary care clinicians may preferentially perform warm handoffs for patients they perceive are the least likely to attend an appointment, such as patients who have severe mental health conditions or substance use disorders, low health literacy, reluctance to engage with behavioral health services, disorganization, social barriers, or other factors. Though our model included some of these potential 
Table 2. Analysis of Patient Characteristics Associated With Attendance at Initial Integrated Behavioral Health Appointments in Primary Care

\begin{tabular}{|c|c|c|c|c|}
\hline Variable & $\begin{array}{l}\text { Unadjusted } \\
\text { OR (95\% CI) }\end{array}$ & $\begin{array}{c}P \\
\text { Value }\end{array}$ & $\begin{array}{c}\text { Adjusted } \\
\text { OR }(95 \% \mathrm{Cl})^{\mathrm{a}}\end{array}$ & $\begin{array}{c}P \\
\text { Value }\end{array}$ \\
\hline \multicolumn{5}{|l|}{ Age, y } \\
\hline $18-40$ & 1.00 & & 1.00 & \\
\hline $41-64$ & $1.20(1.02-1.40)$ & .03 & $1.31(1.1-1.56)$ & .002 \\
\hline$\geq 65$ & $1.25(0.88-1.78)$ & .20 & $1.42(0.96-2.11)$ & .081 \\
\hline \multicolumn{5}{|l|}{ Sex } \\
\hline Female & 1.00 & & 1.00 & \\
\hline Male & 1.19 (1.02-1.39) & .03 & $1.13(0.96-1.33)$ & .15 \\
\hline \multicolumn{5}{|l|}{ Race/ethnicity } \\
\hline $\begin{array}{l}\text { Non-Hispanic black/ } \\
\text { African-American }\end{array}$ & 1.00 & & 1.00 & \\
\hline Hispanic (any race) & $1.14(0.93-1.41)$ & .21 & $1.15(0.93-1.43)$ & .20 \\
\hline Non-Hispanic white & $1.39(1.15-1.68)$ & .0008 & $1.35(1.10-1.67)$ & .004 \\
\hline Other/missing race & $1.35(1.03-1.78)$ & .03 & $1.42(1.07-1.88)$ & .016 \\
\hline \multicolumn{5}{|l|}{ Insurance } \\
\hline Medicaid & 1.00 & & 1.00 & \\
\hline Medicare & $1.06(0.84-1.33)$ & .64 & $0.95(0.73-1.24)$ & .70 \\
\hline Commercial & $1.28(1.06-1.56)$ & .01 & $1.32(1.07-1.61)$ & .008 \\
\hline Other & $1.20(0.84-1.72)$ & .31 & $1.26(0.86-1.83)$ & .23 \\
\hline \multicolumn{5}{|l|}{$\begin{array}{l}\text { Behavioral health } \\
\text { diagnosis }^{b}\end{array}$} \\
\hline Substance use disorder & $0.94(0.77-1.14)$ & .52 & $0.75(0.60-0.95)$ & .016 \\
\hline Bipolar disorder & $0.79(0.50-1.23)$ & .30 & $0.89(0.55-1.46)$ & .66 \\
\hline PTSD & $0.77(0.57-1.05)$ & .10 & $0.74(0.53-1.03)$ & .076 \\
\hline Schizophrenia & $0.79(0.61-1.02)$ & .07 & $0.80(0.61-1.06)$ & .13 \\
\hline Received warm handoff & $1.02(0.84-1.23)$ & .85 & $0.96(0.79-1.18)$ & .71 \\
\hline $\begin{array}{l}\text { Appointment scheduled } \\
\text { on same day as referral }\end{array}$ & $7.62(5.18-11.20)$ & $<.0001$ & $11.66(7.65-17.76)$ & $<.001$ \\
\hline Appointment within $1 \mathrm{mo}$ & $0.96(0.81-1.13)$ & .61 & $1.67(1.37-2.05)$ & $<.001$ \\
\hline \multicolumn{5}{|c|}{ OR = odds ratio; PTSD = posttraumatic stress disorder. } \\
\hline \multicolumn{5}{|c|}{$\begin{array}{l}\text { a Adjusted for age, sex, race, insurance, substance use disorders, bipolar disorder, PTSD, schizophrenia, } \\
\text { and days until next appointment. } \\
\text { b Taken from problem lists in the electronic health record. Reference is not having each diagnosis. }\end{array}$} \\
\hline
\end{tabular}

To read or post commentaries in response to this article, see it online at https:/lwww. AnnFamMed.org/content/16/4/346.

Key words: integrated behavioral health; behavioral health attendance; warm handoffs

Submitted December 16, 2017; submitted, revised, March 26, 2018; accepted April 6, 2018.

Funding support: Dr Pace receives grant support from from a Health Resources and Services Administration award, K02HP30814. Additional support for the data analysis was provided by a Harvard Pilgrim Health Care Quality Grant.

Previous presentations: Findings presented at the Society of Teachers of Family Medicine Conference on Practice Improvement, December 3, 2017.

Acknowledgements: We appreciate the assistance of Linda Rosen in the Clinical Data Warehouse, and Deana Barakat in the Section of General Internal Medicine for her assistance with manuscript preparation.

\section{References}

1. Davis MM, Balasubramanian BA, Cifuentes $M$, et al. Clinician staffing, scheduling, and engagement strategies among primary care practices delivering integrated care. J Am Board Fam Med. 2015;28(Suppl 1):S32-S40.

2. Olfson M, Mojtabai R, Sampson NA, et al. Dropout from outpatient mental health care in the US. Psychiatr Serv. 2009;60(7):898-907.

3. Horevitz E, Organista KC, Arean PA. Depression treatment uptake in integrated primary care: how a "warm handoff" and other factors affect decision making by Latinos. Psychiatr Serv. 2015;66(8):824-830

4. Apostoleris NH. Integrating psychological services into primary care in an underserved community: examining the referral process

confounders, EHR data cannot capture all relevant factors. Another possible explanation is the heterogeneity of warm handoffs conducted in a real-world setting. Ideally, during warm handoffs, behavioral health clinicians establish rapport with patients, deliver brief supportive counseling or a brief intervention, and educate patients about the integrated behavioral health program. In a busy underserved clinic such as ours, however, integrated clinicians may not always have the opportunity to deliver all aspects of a warm handoff, and its potential in improving attendance may not be realized.

A prospective study comparing different types of warm handoffs to standard referrals is needed to determine whether warm handoffs improve attendance at initial intake appointments, and which features of warm handoffs are most beneficial for shich patients. In the interim, reducing appointments wait times is likely to improve attendance at initial behavioral health intakes. for on-site mental health services. Paper presented at: Northeast Regional Conference of the Society of Teachers of Family Medicine 2000; Philadelphia, PA

5. Kreyenbuhl J, Nossel IR, Dixon LB. Disengagement from mental health treatment among individuals with schizophrenia and strategies for facilitating connections to care: a review of the literature. Schizophr Bull. 2009;35(4):696-703.

6. Swift JK, Whipple JL, Sandberg P. A prediction of initial appointment attendance and initial outcome expectations. Psychotherapy (Chic). 2012;49(4):549-556.

7. Hawker DSJ. Increasing initial attendance at mental health out-patient clinics: opt-in systems and other interventions. Psychiatr Bull. 2007; 31(5):179-182.

8. Roberts N, Meade K, Partridge M. The effect of telephone reminders on attendance in respiratory outpatient clinics. J Health Serv Res Policy. 2007;12(2):69-72.

9. Lasser KE, Mintzer IL, Lambert A, Cabral H, Bor DH. Missed appointment rates in primary care: the importance of site of care. J Health Care Poor Underserved. 2005;16(3):475-486.

10. Pillai R, Bhangu N, Narayanan M, Yoong W. A demographic study to profile non-attenders at a gynaecology outpatient clinic. J Obstet Gyn. 2012:32(2):156-158. 